This document is published in:

Journal of Monetary Economics (1998), 42 (1), 93-130.

DOI:http://dx.doi.org/10.1016/S0304-3932(98)00015-4

(C) 1998 Elsevier B.V. 


\title{
Exploring the income distribution business cycle dynamics
}

\author{
Ana Castañeda ${ }^{\mathrm{a}}$, Javier Díaz-Giménez ${ }^{\mathrm{b}}$, José-Victor Ríos-Rull ${ }^{\mathrm{c}, *}$ \\ ${ }^{a}$ Universitat Pompeu Fabra, Barcelona, Spain \\ ${ }^{\mathrm{b}}$ Universidad Carlos III de Madrid, Madrid, Spain \\ ${ }^{\mathrm{c}}$ University of Pennsylvania, Philadelphia, PA 19104, USA
}

\begin{abstract}
We document the business cycle behavior of the US income distribution and explore the extent to which unemployment spells and cyclically-moving factor shares account for this behavior by analyzing four heterogeneous household extensions of the neoclassical growth model. We conclude (i) that partitioning the population into five types subject to type-specific employment processes seems to be enough to account for most aspects of the US income distribution business cycle dynamics, (ii) that the role played by cyclically-moving factor shares is small, and (iii) that the income distribution business cycle dynamics may be essentially independent from the significant part of the observed wealth concentration that these model worlds fail to account for.
\end{abstract}

JEL classification: C68; D31; E32

Keywords: Unemployment; Income distribution fluctuations

\section{Introduction}

Eventhough business cycles, stabilization policies and the income distribution are recurrent themes in both economic and political discussions, very little is

* Corresponding author. Address: Department of Economics, University of Pennsylvania, 3718 Locust Walk, Philadelphia, PA 19104-6297; E-mail: vr0j@anaga.sas.upenn.edu. 
known about the income distribution business cycle dynamics and, consequently, about the distributive impact of stabilization policies. This paper attempts probably a first step in the construction of a reliable quantitative theory of the income distribution business cycle dynamics.

The contribution of this paper is twofold. First, it documents the business cycle behavior of the income distribution. Second, it explores the extent to which unemployment spells and cyclically moving factor shares account for this behavior. To this purpose, we study different heterogeneous household extensions of the neoclassical growth model.

To document the income distribution business cycle facts, we use the US Bureau of the Census summaries of the current population surveys (CPS). These yearly summaries report the total income shares earned by the five quintiles and the top 5\% of the CPS samples during the 1948-86 period. ${ }^{1}$ We have chosen the CPS because it is the only source that provides income distribution time series that are sufficiently long and consistent for our purposes. ${ }^{2}$ We find that the income share earned by the lowest quintile is both the most volatile and the most procyclical. The volatility of the income shares then decreases monotonically until we reach the top two groups when it increases again. We also find that the procyclicality of the income shares displays a similar behavior - it decreases monotonically until we reach the top $5 \% .{ }^{3}$ Graphically, these facts imply that the plots of both the relative volatilities and the correlations with output of the income shares earned by the different income groups when represented in their natural ordering display hook-shapes.

Our candidates to address these facts are unemployment spells and cyclically moving factor shares. We focus on unemployment spells for two reasons: first, because fluctuations in employment are the main contributor to accounting for business cycles; and second, because unemployment spells could play a potentially important role in determining the business cycle dynamics of the left tail of the income distribution. We base this conjecture on the findings of Clark and Summers (1981), Kydland (1984), Ríos-Rull (1993), and others, who document that the impact of unemployment spells is different for different income groups and that the employment of low-income workers is the most procyclical and volatile. We focus on cyclically moving factor shares also, for two reasons: first,

\footnotetext{
${ }^{1}$ Strictly speaking, the $i$ th quintile of a distribution $F$ is the value in support of that distribution that solves the equation $F(x)=0.2 i$. In this paper, we report the shares of total income earned by different groups - the poorest $20 \%$, the next $20 \%$, and so on; however, we abuse the language and call these groups quintiles.

${ }^{2}$ Unfortunately, we have not found any data set of comparable length and degree of consistency that reports labor income and capital income separately.

${ }^{3}$ Specifically, the income shares earned by the fourth quintile and the $80-95 \%$ group are countercyclical, and the share earned by the top $5 \%$ is acyclical.
} 
because in the US economy, the capital share fluctuates with the business cycle and is procyclical; and second, because the procyclical behavior of the capital share could play a potentially important role in determining the business cycle dynamics of the right tail of the income distribution. We base this conjecture on the findings of Díaz-Giménez et al. (1997), who document that the capital income earners belong to the top income groups. Therefore, the procyclical behavior of the capital share will increase both the relative volatility and the correlations with output of the income shares earned by those groups. The main purpose of this paper is to explore these two conjectures.

To address these issues, we construct different heterogeneous household extensions of the stochastic neoclassical growth model. We use this model because it is the most widely used framework for macroeconomic analysis. Consequently, its properties are well understood. Moreover, it is fairly immediate to extend the neoclassical growth structure to include the type of household heterogeneity needed to address the distributional issues considered in this paper.

The model economies that we analyze in this paper share the following features. First, they include two factors of production, labor and capital, and consequently, the model economy households have two income sources, labor income and capital income. We assume that there are competitive markets for both factors. Second, the model economies' employment dynamics are relatively simple: households are subject to an exogenous stochastic process in their employment opportunities, and they work whenever they have the opportunity to do so. We assume that these processes are uninsured and that they have two components: a household-specific component that results in different employment histories for different households and an economy-wide component that generates the business cycles. Third, in all the model economies analyzed in this paper, prices are fully endogenous. ${ }^{4}$ This fact and the competitive factor markets assumption imply that both the labor income and the capital income processes are endogenous to the model. More specifically, both income processes depend, in part, on the individual household savings decisions, which are nontrivial functions of the households' employment histories and of the aggregate state of the economy.

In the first step of our analysis, we explore the income distribution business cycle dynamics in a model economy where we assume that every household is ex ante identical and that they all face the same employment process. This model economy is the closest one to the standard representative household stochastic growth model, and consequently, we consider it to be the obliged starting point

\footnotetext{
${ }^{4}$ This is not the case in İmrohoroğlu (1989), İmrohoroğlu (1992), İmrohoroğlu and Prescott (1991), Díaz-Giménez et al. (1992), Díaz-Giménez and Prescott (1997) and Díaz-Giménez (1997). On the other hand, Krusell and Smith (1996), Krusell and Smith (1997), also use endogenous prices.
} 
in our analysis. Eventhough the income distribution implied by the decisions of ex ante identical households facing the same employment processes does not resemble the income distribution observed in the US, we intend this economy to act as a benchmark against which to compare our results.

We find that in this model economy, unemployment spells alone account for a small share of the income concentration observed in the US $(18 \%$ of our CPS-based measure of the US income Gini index) and that they do a poor job in accounting for the income groups' observed business cycle dynamics. As far as the relative volatilities of the income shares are concerned, this is mainly true because the model economy overestimates the volatility of the income share earned by the lowest quintile. As far as the correlations with output are concerned, this is mainly true because the model economy overestimates the correlation of the income share earned by the lowest quintile, and it underestimates the correlations of the remaining groups. The main reasons that justify these findings are that households who experience long unemployment spells drop to the lowest quintile and that the labor income shares earned by the top groups are exactly the same. Furthermore, both capital and capital income are also too uniformly distributed across households.

The next step in our analysis is to include some features that are likely to generate income distributions that are more concentrated. Since there is no established theory of labor earnings differentials, there is no obvious way to select which features to include. In our second model economy, we use the following procedure: we use Ríos-Rull (1990) summaries of panel study of income dynamics (PSID) data to construct a measure of permanent earnings differences across households, and this measure is used to partition the model economy households into five types. Then we characterize the employment processes specific to each of these household types, and we impose them on the model economy households. This procedure has two advantages: it is relatively simple, and it is entirely based on observables.

In this case, we find that uninsured unemployment spells account for a significantly larger share of the income concentration observed in the US (75\% of our CPS-based measure of the US income Gini index) and that they also account for most aspects of the business cycle behavior of the US income groups. As far as the relative volatilities are concerned, we find that the relative volatility of the income share earned by the lowest quintile almost exactly mimics the volatility observed in the US and that the shares earned by the remaining groups also come closer to mimicking the observed values. As far as the correlations with output are concerned, we also find a significant improvement. In spite of these improvements, we find that in this model economy, wealth is still too disperse. ${ }^{5}$

\footnotetext{
${ }^{5}$ The wealth Gini index in this model economy is only $15 \%$ of our measure of the US wealth Gini index, which we compute from data reported by the survey of consumer finances (SCF).
} 
In fact, in this model economy, wealth is even more disperse than in the benchmark model economy. This is mainly true because the high skill groups of the PSID partition are subject to less volatile employment processes, and consequently, they have smaller incentives to save.

In the next step of our analysis, we explore whether the cyclical behavior of factor shares plays a quantitatively important role in shaping the business cycle behavior of the income groups. To do this, in our third model economy, we modify the aggregate technology of the multiple household-type model economy so that it mimics the observed behavior of US factor shares. We find that cyclical movements in factor shares similar in magnitude to those observed make very little difference for the issues addressed in this paper. Specifically, we find that, in the model economy with five skill groups and cyclically moving factor shares, the income and wealth Gini indices, the relative volatilities of the shares earned by the different income groups, and the correlations of these shares with aggregate output are almost identical to those that obtain in the model economy with five skill groups and constant factor shares.

The three endogenous models of the wealth distribution that we have discussed so far severely underpredict the wealth concentration observed in the US, and this property might condition the model economies' income distribution business cycle dynamics. In the last step of our analysis, we explore whether this is indeed the case. To do this, in our fourth model economy, we take the extreme course of exogenously imposing the US wealth distribution on the model economy with five skill groups and cyclically moving factor shares. Not surprisingly, we find that this exogenous modeling of the wealth distribution increases the income concentration (in this model economy, the income Gini index is $90 \%$ of our CPS-based measure of the US income Gini index) and, by construction, the wealth concentration. In spite of this, when we compare the business cycle dynamics of the income shares earned by the different groups in this model economy with those that obtained in the corresponding model economy with an endogenous wealth distribution, we find that they remain essentially unchanged.

Other recent papers that examine the income distribution dynamics are Banerjee and Newman (1993), Ríos-Rull (1993), Krusell and Smith (1996), Krusell and Smith (1997). Banerjee and Newman (1993) show that the exogenous initial wealth distribution can have quantitatively important implications for long-run growth. Ríos-Rull (1993) examines the labor income dynamics in an overlapping generations framework that abstracts from capital accumulation. Krusell and Smith's papers are closer in spirit to this paper. In their first paper, Krusell and Smith (1996) explore whether the aggregate business cycle dynamics of economies with both idiosyncratic and aggregate shocks are similar to those implied by the standard representative household real business cycle model, and they find that they are. In this paper, Krusell and Smith (1996) make an important methodological contribution. They show that the accuracy of forecasts of future prices based only on the first moment of the wealth distribution is 
surprisingly good. This finding implies that many environments that were previously thought to be intractable with the current computational technology can be addressed in a relatively simple way. In this paper, we exploit this result. In fact, an interesting by-product of our research is the confirmation of Krusell and Smith's methodological finding (Krusell and Smith, 1996). In our economies, the $R^{2}$ of aggregate capital forecasted using their methods is over 0.99999997 in every case that we consider. In a similar vein, Krusell and Smith (1997) examine an environment where both real capital and a riskless bond can be held by the households, and they find that including this additional security does not change the equilibrium allocations in any significant way.

The main conclusions of our analysis are the following: (i) partitioning the population into five types subject to type-specific employment processes seems to be enough to account for most aspects of the US income distribution business cycle dynamics; (ii) the role played by cyclically moving factor shares in accounting for the income distribution business cycle dynamics is small; and (iii) the income distribution business cycle dynamics may be essentially independent from the significant part of the observed wealth concentration that these models fail to explain.

The rest of this paper is organized as follows. In Section 2, we report the business cycle dynamics of the US income distribution. In Section 3, we describe the features that are common to all our model economies. In Sections 4-7, we describe the calibration details specific to each of our four model economies, and we report our findings. Finally, in Section 8, we offer some concluding comments. The paper also contains two appendices. In Appendix A, we describe the aggregate time series. In Appendix B, we describe the computational methods that we use to solve the model economies.

\section{Some facts}

Our primary data sources are the P60 series of the Current Population Reports published by the US Bureau of the Census in various issues of Money Income of Households, Families, and Persons. We have chosen this data set because it is the only one that provides income distribution time series that are sufficiently long and consistent for our purposes. The US Bureau of the Census constructs these series by standardizing the answers to the total income questions asked in the March files of the CPS.

The definition of income considered includes all monetary income earned during the previous year before personal taxes. It includes items such as social security benefits, unemployment compensation, public assistance, retirement benefits and dividends, but it excludes noncash benefits, such as food stamps or health benefits. 
The survey units considered are families and unrelated individuals. These units do not correspond exactly with the National Income and Product Accounts (NIPA) concept of households. The NIPA concept of households considers a group of unrelated individuals sharing a housing unit as one household, and it counts live-in employees as part of their employers' households. The concept of families and unrelated individuals considers both unrelated individuals and live-in employees as different units. The US Bureau of the Census has only been reporting data for NIPA households since 1967. This leads us to use the data on families and unrelated individuals, which have been reported since 1948.

Since the questions used to construct the data appear in the March files of the CPS only, the data are reported yearly. ${ }^{6}$ The sample period available is $1948-86$.

The US Bureau of the Census reports the shares of total income earned by the five quintiles and by the top 5\% of the income distribution of the sample units. Unlike other data sources, in the CPS, every household whose yearly income is greater than a given threshold - typically 100,000 - is reported as earning that threshold, a procedure which is technically known as top coding. This procedure effectively ignores most of the top tail of the distribution and biases the concentration measures downward.

We use the US Bureau of the Census data to construct average and business cycle statistics for the income shares earned by the lowest four quintiles, the next $15 \%$, and the top $5 \%$ of the income distribution. We report the average income shares earned by these groups and an approximation to the income Gini index computed from these averages in the first row of Table $1 .^{7}$ To compute the business cycle statistics, we log every variable except the ones that report either shares or rates, and we detrend the resulting series using the Hodrick and Prescott filter with a smoothing parameter of $\lambda=100 .{ }^{8}$ In the cases of rates and shares, we report the coefficients of variation instead of the standard deviations. We report the full set of standard business cycle statistics in Table 2.

Since this set of statistics is fairly large, to summarize our findings, we focus on the volatilities relative to aggregate output and on the correlations with output of the income shares earned by the income groups, which we report in the first rows of Tables 3 and 4, respectively. We find that when plotted in their natural

\footnotetext{
${ }^{6}$ The frequency with which the data are collected is important. The reason for this is that income differences across households that arise from unemployment spells decrease with the length of the period being considered, since unemployment spells tend to average out over time.

${ }^{7}$ This is an approximation to the Gini index, since we use only six observations to approximate the Lorenz curve. The true value of the Gini index is somewhat higher. In this paper, we use exactly the same approximation to compute the concentration indicators of the model economies.

${ }^{8}$ For details on the properties of the Hodrick and Prescott filter, see Cooley and Prescott (1995). Two other papers that analyze the business cycle properties of yearly series are Backus and Kehoe (1992) and Ríos-Rull (1996).
} 
Table 1

Average income distributions

\begin{tabular}{lcrrrrrrr}
\hline & \multirow{2}{*}{ Gini } & \multicolumn{4}{c}{ Quintiles } & \multicolumn{3}{c}{ Top groups (\%) } \\
Economy & & 1st & 2nd & 3rd & 4th & 5th & $80-95$ & $95-100$ \\
\hline US & 0.351 & 5.05 & 11.95 & 17.56 & 23.91 & 41.53 & 25.56 & 15.97 \\
& & & & & & & & \\
Benchmark model & 0.064 & 15.21 & 19.81 & 21.14 & 21.58 & 22.26 & 16.56 & 5.70 \\
P model & 0.257 & 8.89 & 13.86 & 17.94 & 23.08 & 36.23 & 26.49 & 9.74 \\
PS model & 0.258 & 8.86 & 13.83 & 17.94 & 23.12 & 36.25 & 26.50 & 9.75 \\
PSW model & 0.315 & 6.90 & 12.30 & 17.30 & 23.80 & 39.60 & 26.30 & 13.30 \\
\hline
\end{tabular}

Notes: The Gini indices have been calculated using the shares earned or owned by the first four quintiles and the two top groups. In the benchmark model economy, there is only one household type, the wealth distribution is endogenous, and the labor share is deterministic. The $\mathrm{P}$ model economy is an extension of the benchmark model economy in which households are partitioned into five skill groups that face different employment processes calibrated to those observed in a similar partition of the PSID sample. The PS model economy is an extension of the P model economy, which is calibrated to display cyclically moving factor shares. The PSW model economy is an extension of the PS model economy on which the US wealth is imposed exogenously.

Table 2

Cyclical behavior of the US economy: 1948-86 (deviations from trend)

\begin{tabular}{|c|c|c|c|c|c|c|c|}
\hline \multirow[b]{2}{*}{ Variable $(x)$} & \multicolumn{7}{|c|}{ Cross correlations of output with } \\
\hline & $\sigma_{x}$ & $\sigma_{x} / \sigma_{y}$ & $x(t-2)$ & $x(t-1)$ & $x(t)$ & $x(t+1)$ & $x(t+2)$ \\
\hline Output $(y)$ & 2.63 & 1.00 & 0.02 & 0.56 & 1.00 & 0.56 & 0.02 \\
\hline Consumption & 1.27 & 0.48 & -0.16 & 0.39 & 0.78 & 0.53 & 0.19 \\
\hline Investment & 7.86 & 2.98 & 0.07 & 0.48 & 0.70 & -0.01 & -0.33 \\
\hline $\begin{array}{l}\text { Total hours } \\
\text { (household) }\end{array}$ & 1.74 & 0.66 & -0.17 & 0.24 & 0.79 & 0.45 & -0.10 \\
\hline $\begin{array}{l}\text { Productivity } \\
\text { per hour }\end{array}$ & 1.66 & 0.63 & 0.25 & 0.65 & 0.77 & 0.39 & 0.09 \\
\hline Employment & 1.26 & 0.48 & -0.30 & 0.10 & 0.71 & 0.46 & -0.02 \\
\hline $\begin{array}{l}\text { Productivity } \\
\text { per person }\end{array}$ & 1.96 & 0.74 & 0.22 & 0.68 & 0.89 & 0.47 & 0.05 \\
\hline Labor share & 0.66 & 0.25 & -0.42 & -0.41 & -0.10 & 0.39 & 0.30 \\
\hline $\begin{array}{l}\text { Lowest quintile } \\
\qquad(0-20 \%)\end{array}$ & 2.83 & 1.07 & -0.17 & 0.04 & 0.53 & 0.36 & 0.05 \\
\hline $\begin{array}{l}\text { Second quintile } \\
\quad(20-40 \%)\end{array}$ & 1.26 & 0.48 & -0.19 & -0.01 & 0.49 & 0.52 & 0.31 \\
\hline $\begin{array}{l}\text { Third quintile } \\
(40-60 \%)\end{array}$ & 0.69 & 0.26 & -0.06 & -0.04 & 0.31 & 0.33 & 0.41 \\
\hline $\begin{array}{l}\text { Fourth quintile } \\
\quad(60-80 \%)\end{array}$ & 0.46 & 0.18 & 0.09 & -0.19 & -0.29 & -0.10 & 0.07 \\
\hline $\begin{array}{l}\text { Next } 15 \% \\
\quad(80-95 \%)\end{array}$ & 0.94 & 0.35 & 0.04 & -0.28 & -0.64 & -0.39 & -0.03 \\
\hline $\begin{array}{l}\text { Top } 5 \% \\
\quad(95-100 \%)\end{array}$ & 1.95 & 0.74 & 0.13 & 0.29 & 0.00 & -0.20 & -0.37 \\
\hline
\end{tabular}

Sources: Citibank database and CPS March files. 


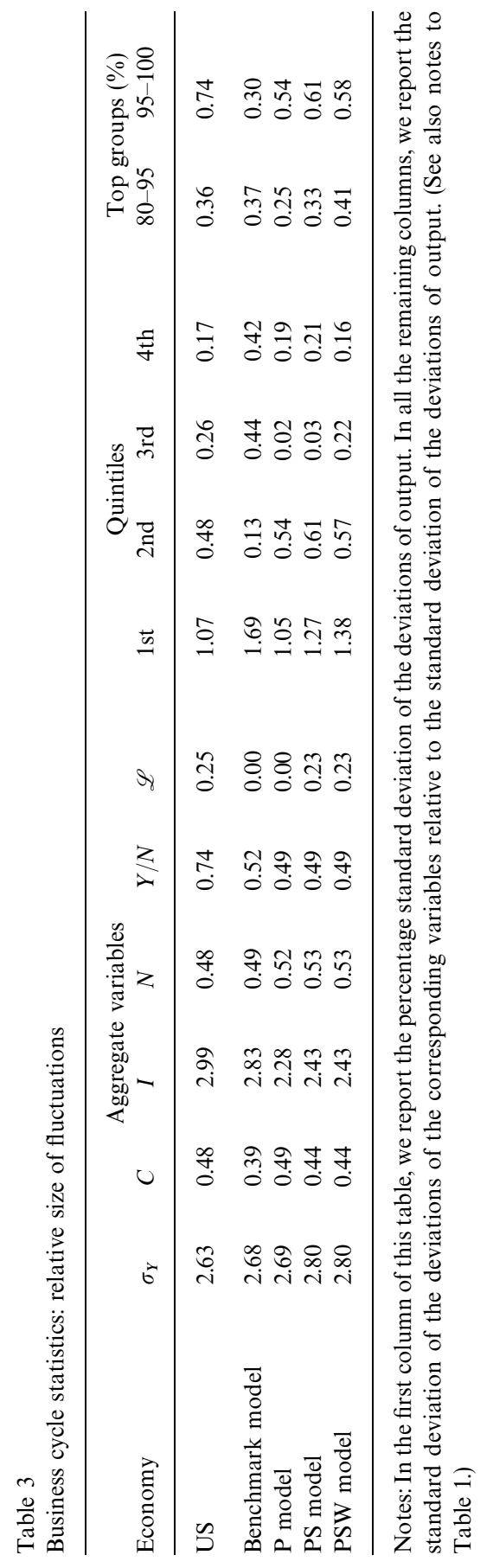




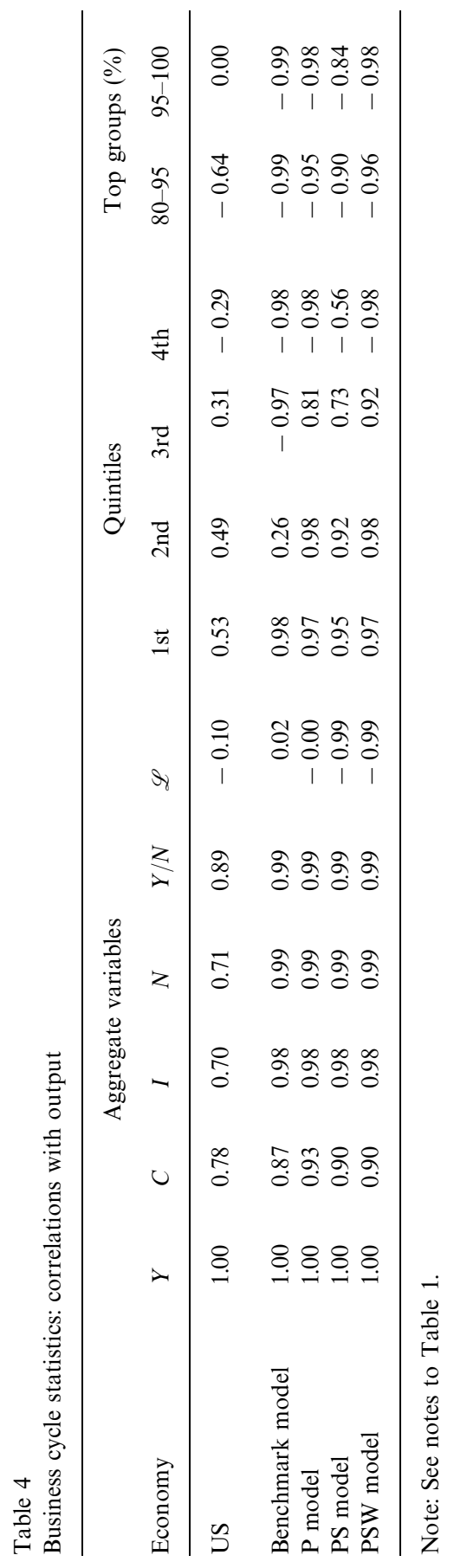



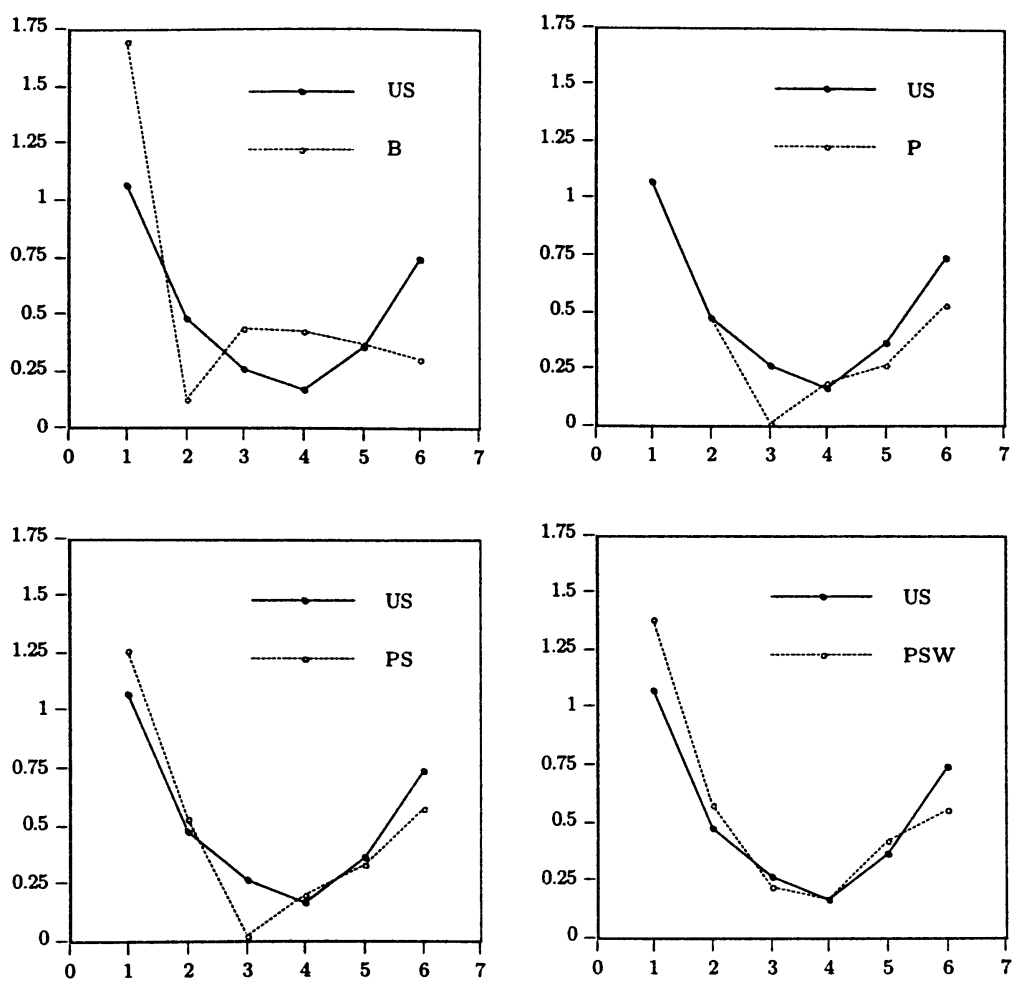

Fig. 1. The relative size of fluctuations of the income quintiles (the US economy and the benchmark, P, PS and PSW model economies). On the bottom scales, labels 1-4 refer to the quintiles, 5 refers to the $80-95 \%$ group, and 6 refers to the top $5 \%$.

ordering, the plots of these two sets of statistics display clear hook-shapes (see Figs. 1 and 2). As we have already mentioned, by hook-shapes, we mean that the highest value of both statistics corresponds to the lowest quintile; then they decrease monotonically as we move towards the upper tail of the distribution; and finally, they increase again when we reach the top groups.

\section{The model economies}

The model economies analyzed in this paper are modified versions of the stochastic neoclassical growth model. These models can also be interpreted as extensions of Aiyagari (1994) and of Huggett (1993), who analyze model worlds that are similar to ours but that do not include either aggregate uncertainty or type multiplicity. The key features of the model economies analyzed in this 

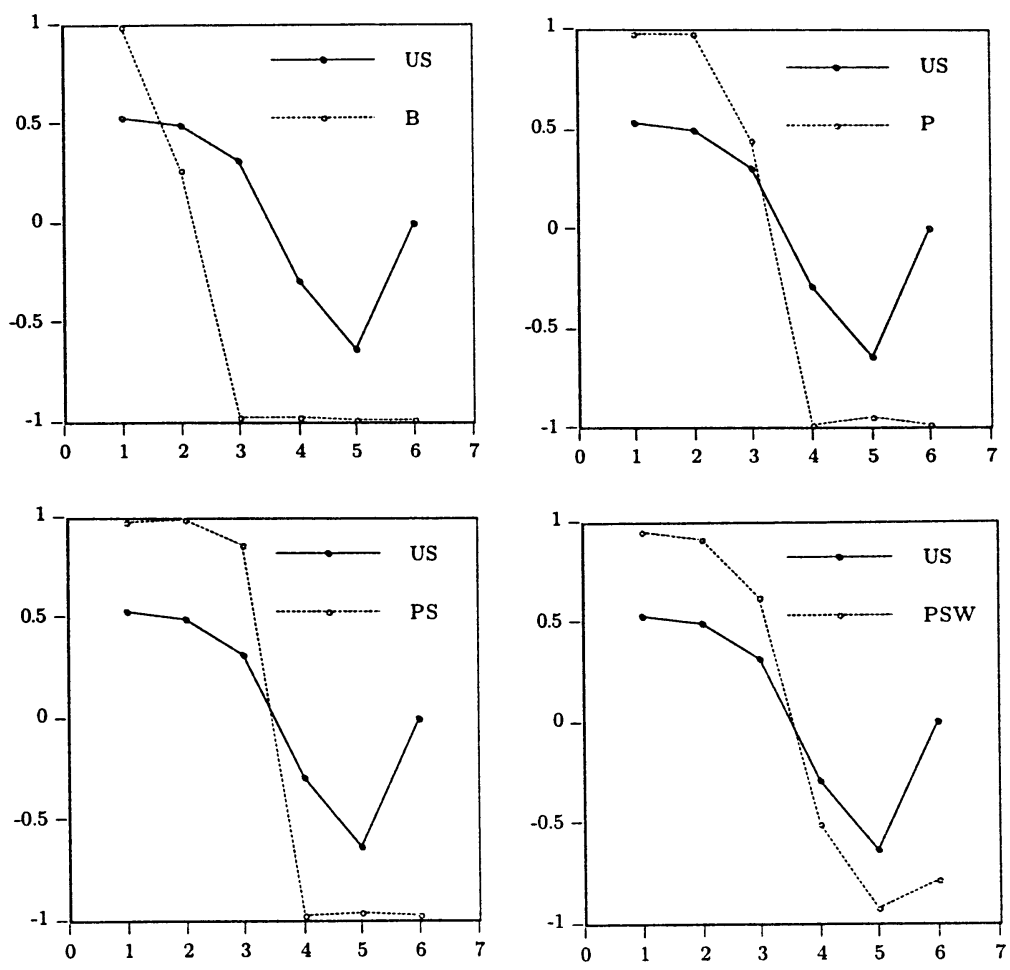

Fig. 2. The correlations with output of the income quintiles (the US economy and the benchmark, P, PS and PSW model economies). On the bottom scales, labels 1-4 refer to the quintiles, 5 refers to the $80-95 \%$ group, and 6 refers to the top $5 \%$.

paper are: (i) they include a large number of heterogeneous households; (ii) the households face both an uninsured, household-specific employment shock and an economywide productivity shock; and (iii) the households accumulate assets both for precautionary reasons as a substitute of insurance against these shocks and for the standard real business cycle motive of taking advantage of higher expected future rates of return.

\subsection{Population}

We assume that at each point in time, the economy is inhabited by a continuum of households of different types, $i \in \mathscr{I} \equiv\{1, \ldots, I\}$. The mass of households of type $i$ is $\mu_{i}$, and $\sum_{i \in \mathscr{I}} \mu_{i}=1$. Household types differ in their efficiency labor factor, $\varepsilon_{i}$, and in the transition probabilities of their idiosyncratic employment processes, $\pi_{i}$, which we describe below. 


\subsection{Preferences}

We assume that households order their random streams of consumption according to

$$
E_{0}\left\{\sum_{t=0}^{\infty} \beta^{t} u\left(c_{i t}\right)\right\}
$$

where $u$ is a continuous and a strictly concave utility function, $0<\beta<1$ is the subjective time discount factor, and $c_{i t} \geq 0$ is the household's allocation of the period $t$ perishable consumption good.

\subsection{Technology}

\subsubsection{Stochastic processes}

We assume that there is an exogenous economy-wide stochastic process, $\left\{z_{t}\right\}$. This process follows a stationary finite-state Markov chain with transition probabilities given by $\Pi\left(z^{\prime} \mid z\right)=\operatorname{Pr}\left\{z_{t+1}=z^{\prime} \mid z_{t}=z\right\}$, where $z, z^{\prime} \in Z=$ $\left\{1,2, \ldots, n_{z}\right\}$. We assume that the Markov chain generating $z$ is such that it has a single ergodic set, no transient states, and no cyclically moving subsets.

We assume that each household type also faces an idiosyncratic random disturbance, $s$, that determines its employment opportunities. Conditional on the realizations of $z_{t}$ and $z_{t+1}$, these idiosyncratic disturbances are assumed to be independently distributed across households and identically distributed within each household type. We assume that the process on these household-type specific employment shocks, $\left\{s_{t}\right\}$, also follows a finite-state Markov chain with conditional transition probabilities given by $\pi_{i}\left(s^{\prime} \mid s, z, z^{\prime}\right)=\operatorname{Pr}\left\{s_{t+1}=s^{\prime} \mid s_{t}=s\right.$, $\left.z_{t}=z, z_{t+1}=z^{\prime}\right\}$, where $s, s^{\prime} \in S=\left\{1,2, \ldots, n_{s}\right\}$ and $z, z^{\prime} \in Z$.

Consequently, the joint processes on $(s, z)$ are Markov chains with $n=n_{s} \times n_{z}$ states. Their transition probabilities are

$$
\Gamma_{i}\left[\left(s^{\prime}, z^{\prime}\right) \mid(s, z)\right]=\operatorname{Pr}\left\{s_{t+1}=s^{\prime}, z_{t+1}=z^{\prime} \mid s_{t}=s, z_{t}=z\right\} .
$$

Households know the laws of motion of both $\left\{s_{t}\right\}$ and $\left\{z_{t}\right\}$, and they observe the realizations of both stochastic processes at the beginning of each period. ${ }^{9}$

\subsubsection{Market production}

We assume that aggregate output, $Y_{t}$, depends on aggregate capital, $K_{t}$, on the aggregate labor input, $L_{t}$, and on the economywide shock, $z_{t}$, through a constant returns to scale aggregate production function, $Y_{t}=f\left(K_{t}, L_{t}, z_{t}\right)$. We also assume that the capital stock depreciates exponentially at a constant rate $\delta$.

\footnotetext{
${ }^{9}$ Note that $\Gamma_{i}\left(., z^{\prime} \mid ., z\right)=\Gamma_{j}\left(., z^{\prime} \mid ., z\right)$ for all $i, j \in \mathscr{I}$.
} 


\subsubsection{Home production}

We assume that every household has access to the same home production technology. In any given period, this technology allows households to produce $\bar{w}$ units of that period's consumption good without using any capital. ${ }^{10}$

\subsubsection{Employment opportunities}

We assume that the household-type specific employment processes take two possible values, $s \in S=\{e, u\}$. When a household of type $i$ draws shock $e$, it receives an endowment of $\varepsilon_{i} h\left(z_{t}\right)>0$ efficiency labor units, which it allocates inelastically to the market, and we say that it is employed. Parameter $\varepsilon_{i}$ is the household-type specific efficiency factor, and function $h(z)$ denotes the endowment of productive time. We assume that every household type works the same number of hours when employed, $h$, and that $h$ depends on the current realization of the economywide shock, $z_{t}$, only. ${ }^{11}$ When a household draws shock $u$, it receives no endowment of productive time. We assume that these households operate the home production technology, and we say that they are unemployed. We denote the measure of households of type $i$ that draw shock $e$ by $N_{i}\left(z_{t}\right)$. Consequently, aggregate employment, $N\left(z_{t}\right)$, is the sum over household types of the measures employed of each type; that is, $N\left(z_{t}\right)=\sum_{i \in \mathscr{I}} N_{i}\left(z_{t}\right)$. The aggregate labor input, $L\left(z_{t}\right)$, is the sum over household types of the measures employed of each type weighted by the number of efficiency labor units supplied by each type; that is, $L\left(z_{t}\right)=\sum_{i \in \mathscr{Y}} \varepsilon_{i} h\left(z_{t}\right) N_{i}\left(z_{t}\right)^{12}$

\subsection{Market arrangements}

We assume that there are no insurance markets for the household-specific shock, s. ${ }^{13}$ We also assume that there are no markets for contracts contingent on

${ }^{10}$ Alternatively, the returns to the home production technology, $\bar{w}$, could be thought of as some form of unemployment compensation. In this case, the model economy would have to include a public sector to levy the resources required to finance the unemployment compensation scheme.

${ }^{11} \mathrm{We}$ make this assumption because we have not found readily available separate data on both hours per worker and employment per worker for suitable partitions of the population into skill groups or types.

${ }^{12}$ Note that for computational considerations, we restrict the type-specific employment to be a function of the current realization of the aggregate shock, $z_{t}$, only. This restriction implies that both aggregate employment and aggregate labor input are also functions of $z_{t}$ only. We discuss this restriction below.

${ }^{13}$ This is a key feature of this class of model worlds. Under the appropriate initial conditions, if insurance markets are allowed to operate, this economy collapses to a standard representative household model. 
the realization of the economywide shock, $z$. Implicitly, these market restrictions also exclude arrangements that implement history-dependent allocations such as those described, for instance, in Atkeson and Lucas (1992) and Atkeson and Lucas (1995). In this paper, we are interested in the aggregate and distributional consequences of a specific set of market arrangements. We do not attempt to account for the reasons that justify the existence of those markets. ${ }^{14}$ To buffer their streams of consumption against these shocks, households can accumulate assets in the form of real capital. Moreover, household asset holdings are restricted to belonging to a compact set $\mathscr{A} .^{15}$

Finally, we assume that firms rent their factors of production from households in competitive spot markets. Consequently, factor prices are given by the corresponding marginal productivities; that is, $r_{t}=f_{1}\left(K_{t}, L_{t}, z_{t}\right)+(1-\delta)$, and $w_{t}=f_{2}\left(K_{t}, L_{t}, z_{t}\right)$, where $r_{t}$ denotes the gross real rental price of capital, and $w_{t}$ denotes the real wage. ${ }^{16}$

\subsection{Equilibrium}

The restrictions that we have imposed on the market structure of our model economies allow us to consider recursive, (i.e. stationary Markov), equilibria only. In the subsections below, we describe the household decision problem and define equilibrium.

\footnotetext{
${ }^{14}$ Note that this limited market structure leaves some room for households to increase their welfare by creating new markets. However, Díaz-Giménez (1990) and others show that in this class of model worlds, buffer stocks can be very good substitutes of insurance in welfare terms; hence, it is unlikely that a small improvement in the insurance possibilities would have large effects on the equilibrium allocations. For instance, Ríos-Rull (1994) compares the equilibrium allocations of heterogeneous household economies that differ in the market structure for aggregate shocks, and he finds that the differences in the behavior of these economies are very small. And, as we have already mentioned, Krusell and Smith (1997) show that the aggregate consequences of introducing a riskless bond in this class of model worlds are also very small. Furthermore, when markets for contracts that are contingent on the aggregate state of the economy are precluded, the equilibrium is significantly easier to compute.
}

${ }^{15}$ Aiyagari (1994) shows that in this class of incomplete market economies, the requirement that debt has to be repaid imposes a lower bound on the set of asset holdings endogenously. Huggett (1993) and Aiyagari (1994) show that in deterministic versions of this economy, as long as the rate of return is lower than the rate of time preference, asset holdings are also bounded above. In this paper, we assume that the lower bound of set $\mathscr{A}$ is zero. This assumption can be interpreted as a borrowing constraint.

${ }^{16}$ In this class of model economies, firms do not play any intertemporal role for two main reasons: first, they do not make any profits, and second, they cannot be used by the households who own them to substitute for insurance by choosing non-profit-maximizing strategies. 


\subsubsection{The household decision problem}

For each household type $i$, the individual state variable is the vector $(a, s, \mu, z)$, which includes the stock of assets held, $a$, the realization of the employment shock, $s$, and the economywide state, $(\mu, z) .{ }^{17}$ The decision problem of a household of type $i$ can be written as

$$
\begin{aligned}
& v_{i}(a, s, \mu, z)=\max _{c \geq 0, a^{\prime} \in \mathscr{A}}\left\{u(c)+\beta \sum_{s^{\prime}, z^{\prime}} v_{i}\left(a^{\prime}, s^{\prime}, \mu^{\prime}, z^{\prime}\right) \Gamma_{i}\left[\left(s^{\prime}, z^{\prime}\right) \mid(s, z)\right]\right\} \\
& c+a^{\prime}=a r+w \varepsilon_{i} h(z) \quad \text { if } s=e, \\
& c \quad \text { if } s=u, a^{\prime}=a r+\bar{w} \quad \\
& r=r(\mu, z), \\
& w=w(\mu, z), \\
& \mu^{\prime}=g\left(\mu, z, z^{\prime}\right),
\end{aligned}
$$

where function $v_{i}$ is the value function of a type $i$ household, $r$ and $w$ are functions that describe the factor prices, and function $g$ describes the law of motion of the wealth distribution. ${ }^{18}$

\subsubsection{Definition of equilibrium}

A recursive competitive equilibrium is a set of household policies, $\left\{c_{i}(a, s, \mu, z), \psi_{i}(a, s, \mu, z), a_{i}^{\prime}(a, s, \mu, z)\right\}_{i \in \mathscr{F}}$, pricing processes $r(\mu, z)$ and $w(\mu, z)$, aggregate input functions, $K(\mu)$ and $L(\mu, z)$, and a law of motion for the distribution of household types, $\mu^{\prime}=g\left(\mu, z, z^{\prime}\right)$, such that

(i) Optimality: given $g\left(\mu, z, z^{\prime}\right), r(\mu, z)$, and $w(\mu, z)$, the household decision rules solve the maximization problems described in Eq. (3), and factor prices are factor marginal productivities:

$$
r(\mu, z)=f_{1}(K(\mu), L(\mu, z), z)+(1-\delta) \quad \text { and } \quad w(\mu, z)=f_{2}(K(\mu), L(\mu, z), z) .
$$

(ii) Feasibility:

$$
\begin{aligned}
& \int_{\mathscr{I}, \mathscr{A}, S}\left(a_{i}^{\prime}(a, s, \mu, z)+c_{i}(a, s, \mu, z)-\psi_{i}(a, s, \mu, z)\right) d \mu \\
& \leq f(K(\mu), L(\mu, z), z)+(1-\delta) K(\mu) .
\end{aligned}
$$

\footnotetext{
${ }^{17}$ Note that $\mu$ is a measure defined over $\mathscr{B}$, an appropriate family of subsets of $\{\mathscr{I} \times \mathscr{A} \times S\}$. We do not need to keep track of household names because the decisions of households in the same $(a, s)$-state are always the same.

${ }^{18}$ Note that because of home production, aggregate consumption is different from market consumption. To compute the amount of the period good produced at home, we define function $\psi_{i}(a, s, \mu, z)$, where $\psi_{i}(a, e, \mu, z)=0$, and $\psi_{i}(a, u, \mu, z)=\bar{w}$.
} 
(iii) Aggregation: factor inputs are generated by aggregation over agents:

$$
K(\mu)=\int_{\mathscr{I}, \mathscr{A}, S} a \mathrm{~d} \mu \quad \text { and } \quad L(\mu, z)=\int_{\mathscr{I}, \mathscr{A}, S} \varepsilon_{i} h(z) \xi_{s=e} \mathrm{~d} \mu,
$$

where $\xi$ is the indicator function.

(iv) Consistency of individual and aggregate behavior:

$$
\begin{aligned}
& \mu^{\prime}\left(\mathscr{I}_{0}, \mathscr{A}_{0}, S_{0}\right)=g\left(\mathscr{I}_{0}, \mathscr{A}_{0}, S_{0}\right)\left(\mu, z, z^{\prime}\right) \\
& =\int_{\mathscr{A}_{0}, S_{0}}\left\{\int_{\mathscr{I}_{0}, \mathscr{A}, S} \xi_{a^{\prime}=a_{i}^{\prime}(a, s, \mu, z)} \Gamma_{i}\left(s^{\prime}, z^{\prime} \mid s, z\right) \mathrm{d} \mu\right\} \mathrm{d} a^{\prime} \mathrm{d} s^{\prime}
\end{aligned}
$$

for all $\left(\mathscr{I}_{0}, \mathscr{A}_{0}, S_{0}\right) \in \mathscr{B}$ and all $\left(\mu, z, z^{\prime}\right)$.

In Appendix B, we describe an approximation to this equilibrium, and provide the algorithm that we use to compute its solution. As we have already mentioned, this algorithm is based on Krusell and Smith (1996).

\subsection{Calibration}

In this section, we discuss the calibration targets and the functional forms and parameters that are common to every model economy. The calibration of the parameters that are specific to each model economy is discussed in the appropriate sections below.

\subsubsection{Model period}

The CPS data on the US income distribution are collected yearly. The appropriate length of the period to model unemployment spells is much shorter - it is probably as short as one week. In our model economies, the model period cannot be longer than the shortest employment or unemployment spell. A weekly model period imposes very high computational costs. As a compromise, we choose one-eighth of a year or six and a half weeks for our model period. ${ }^{19}$

\subsubsection{Preferences}

To characterize the household decision problem, we must choose a specific form for the utility function. As is customary in quantitative general equilibrium exercises, we choose a constant relative risk aversion utility function. Our choice

\footnotetext{
${ }^{19}$ Note that the model period need not coincide with the data collection or reporting period. In this paper, the model period is $1 / 8$ of an year, but the data collection and reporting period is yearly.
} 
for the risk aversion coefficient is $\sigma=1.5$. This is in line with many other studies. $^{20}$

We target a value for the net real rate of return of $4 \%$ for the deterministic version of the model economies. The value of the households' common subjective time discount factor that implements this choice is $\beta=0.96$.

\subsubsection{Technology}

We choose the functional forms and parameters so that our model economies mimic as closely as possible the following US economy statistics:

(i) Consumption-output ratio. In the model economies, output is the sum of consumption and investment. Therefore, the first statistic that we want to match is the ratio of consumption to the sum of consumption and investment. In the US economy, this ratio is $72.8 \%$.

(ii) Factor shares. After World War II factor shares in the US have displayed no trend. To account for this property, we choose a Cobb-Douglas aggregate production function, $Y_{t}=z_{t} K_{t}^{\theta} L_{t}^{1-\theta}$, where $\theta$ is the capital share. ${ }^{21}$ To construct our measure of the U.S. economy capital share, we follow Cooley and Prescott (1995), but we abstract from the role played by the government. ${ }^{22}$ When measured in this way, the value for the capital share for the US economy is 0.375 .

(iii) Average employment rate. Our model economies are too abstract to distinguish between households that are outside the labor force and households that are unemployed. Moreover, in the US economy, the labor-force participation is strongly procyclical. To address this issue, we interpret the lower labor-force participation in downturns as discouraged workers, that is, as people who do not have an employment opportunity. Under this interpretation, to determine the average employment rate in our model economy, we divide the average employment rate in the US during the period under consideration (which was $62 \%$ ) by one of the highest values for the US labor-force participation rate in that same period $(67 \%)$, and we obtain a value of $92 \%$, which is the value for the average employment rate that we target. ${ }^{23}$ Of course, our choice

\footnotetext{
${ }^{20}$ See Mehra and Prescott (1985) or, more recently, Kocherlakota (1996) for a description of some of those studies.

${ }^{21}$ Note that this functional form generates factor shares that are constant at every frequency. On the other hand, in the US, the labor share is countercyclical (see Table 2). This issue is addressed in Section 6, where we construct a model economy with cyclically moving factor shares.

${ }^{22}$ Essentially, their procedure considers consumer durables as capital goods, and therefore, they adjust the NIPA measure of output to include the flow of services from consumer durables. Details on how our measure of the labor share was constructed can be found in Appendix A.

${ }^{23}$ This choice is fairly standard in the literature. See İmrohoroğlu (1989), Díaz-Giménez et al. (1992), and Díaz-Giménez (1997), amongst others.
} 
implies higher average unemployment rates than those reported by the Bureau of Labor Statistics.

(iv) Output volatility. We target the volatility of logged, detrended output in the model economy to match the value of $2.63 \%$ observed in yearly US data.

(v) Employment volatility. We target the volatility of logged, detrended employment in the model economy to match the value of $1.26 \%$ observed in yearly US data.

(vi) Persistence of business cycles. We target the autocorrelation of logged, detrended yearly output to match the value of 0.56 observed in yearly US data.

(vii) Symmetric business cycles. We assume that the economywide shock, $z$, takes two values: $z \in Z=\left\{z_{1}, z_{2}\right\}$, which represent, expansions and recessions, respectively, and we assume that the expected durations of expansions and recessions coincide. This assumption is customarily made in most quantitative studies of business cycles, and it requires that $\Pi\left(z_{1} \mid z_{1}\right)=\Pi\left(z_{2} \mid z_{2}\right)$.

(viii) and (ix) Expected duration of unemployment spells. We assume that the average duration of unemployment spells is 10 weeks during expansions and 14 weeks during recessions. İmrohoroğlu (1989) and Díaz-Giménez (1997) make these same choices.

(x) Efficiency labor factors. We must choose the relative efficiency labor factors of each household type, $\varepsilon_{i}$. In the single-type model economy, the relative efficiency factor is, trivially, $\varepsilon=1$. In the multiple-type model economy, we use Ríos-Rull (1990) estimates of the relative efficiency factors (see below).

(xi)-(xiv) The aggregate labor input and the economywide process. In heterogeneous household economies, households need to know the aggregate labor input, $L_{t}$, in order to compute prices. This makes $L_{t}$ a state variable. This feature imposes very high computational costs. To get around this problem, we make aggregate employment, $N_{t}$, and, hence, $L_{t}$ a function of the current realization of the economywide process only. This leads us to impose the following four additional restrictions:

$$
N\left(z^{\prime}\right)=\int_{\mathscr{A}} \pi\left(e \mid e, z, z^{\prime}\right) \mathrm{d} \mu(a, e)+\int_{\mathscr{A}} \pi\left(e \mid u, z, z^{\prime}\right) \mathrm{d} \mu(a, u),
$$

one for $\operatorname{each}\left(z, z^{\prime}\right) \in Z \times Z$.

(xv) and (xvi) Individual employment immediately after transitions. Conditions (xi)-(xiv) imply that when there is a switch in the economywide shock, $z_{t}$, aggregate employment changes. Therefore, the employment status of households immediately after switches must be determined somehow. To this purpose, we assume that in the switches from expansions to recessions, all previously unemployed households remain unemployed and that in the switches from recessions to expansions, all previously employed households remain employed. 
To achieve these targets, we calibrate the following 16 parameters: the depreciation rate, $\delta$, the capital share, $\theta$, the two conditional transition probabilities of the economywide shocks, $\Pi\left(z^{\prime} \mid z\right)$, parameter $z_{2} h(z)^{1-\theta},{ }^{24}$ and the following 11 type-specific parameters: the efficiency labor factor, $\varepsilon_{i}$, aggregate employment in both states, $N_{i}\left(z_{1}\right)$ and $N_{i}\left(z_{2}\right)$, and eight conditional transition probability parameters on the household-specific shocks, $\pi_{i}\left(s^{\prime} \mid s, z, z^{\prime}\right) .{ }^{25}$ Note that these parameters differ in the different model economies, and we discuss them in the appropriate sections below.

Finally, we must calibrate the home production technology. The returns to this technology represent the value to the households of their endowment of time when they do not work in the market measured in terms of current-period consumption. This parameter is difficult to choose. We assume that in our model economies, the value of home production is time invariant and that it is $25 \%$ of the average earnings.

\section{The benchmark model economy}

In the benchmark model economy, we assume that there is only one household type. As we have already mentioned, this model economy is the closest one to the standard representative household stochastic growth model, and consequently, we consider it to be the obliged starting point in our exploration of the income distribution business cycle dynamics. Even though our findings confirm that the equilibrium income distribution does not resemble the one observed in the US, we intend this economy to act as a benchmark against which to compare our results.

\subsection{Calibration}

In the benchmark model economy, there is only one type of household. Consequently, $i=1$, and $\mu_{1}=1 .^{26}$

\footnotetext{
${ }^{24}$ Recall that we have chosen a Cobb-Douglas aggregate production function, $Y=z K^{\theta} L^{1-\theta}$, where $L=\sum_{i} \varepsilon_{i} h(z) N_{i}(z)$ is the labor input measured in efficiency units. Consequently, we can rewrite the aggregate production function as $Y=z K^{\theta} L^{1-\theta}=z h(z)^{1-\theta} K^{\theta}\left[\sum_{i} \varepsilon_{i} N_{i}(z)\right]^{1-\theta}$. Hence, for each household type, we do not have to decompose $z h(z)$ into its components, and we simply choose a number for the product $z h(z)^{1-\theta}$. Moreover, we use $z_{1} h\left(z_{1}\right)^{1-\theta}$ as our unit normalization criterion, and let $z_{1} h\left(z_{1}\right)^{1-\theta}=1$. This leaves us with only parameter $z_{2} h\left(z_{2}\right)^{1-\theta}$ to be determined.

${ }^{25}$ For each household type, there are twelve transition probability parameters to be determined. However, the requirement that restrictions (xi)-(xiv) must be satisfied implies the loss of four degrees of freedom.

${ }^{26}$ Note that we have abused the language somewhat, and we have chosen $\mu$ to denote the measure of households and $\mu_{i}$ to denote the mass of households of type $i$.
} 
Table 5

The benchmark model economy: calibrated technology parameters (in yearly terms)

\begin{tabular}{llll}
\hline Parameter & Value & Parameter & Value \\
\hline$\delta$ & 0.1000 & $\theta$ & 0.3750 \\
$\Pi\left(z_{2} \mid z_{2}\right)$ & 0.9722 & $\varepsilon$ & 1.0000 \\
$\pi\left(e \mid e, z_{1}, z_{1}\right)$ & 0.9615 & $\pi\left(u \mid u, z_{1}, z_{1}\right)$ & 0.0419 \\
$\pi\left(e \mid e, z_{1}, z_{2}\right)$ & 0.9580 & $\pi\left(u \mid u, z_{1}, z_{2}\right)$ & 1.0000 \\
$z_{2} h\left(z_{2}\right)^{1-\theta}$ & 0.9130 & $\Pi\left(z_{1} \mid z_{1}\right)$ & 0.9722 \\
$N\left(z_{1}\right)$ & 0.9594 & $N\left(z_{2}\right)$ & 0.8806 \\
$\pi\left(e \mid e, z_{2}, z_{2}\right)$ & 0.9525 & $\pi\left(u \mid u, z_{2}, z_{2}\right)$ & 0.5714 \\
$\pi\left(e \mid e, z_{2}, z_{1}\right)$ & 1.0000 & $\pi\left(u \mid u, z_{2}, z_{1}\right)$ & 0.6048 \\
\hline
\end{tabular}

In the benchmark model economy, the parameter values that achieve our calibration targets are shown in Table 5 .

\subsection{Findings}

Once we have completely specified the functional forms and parameters of our benchmark model economy, we compute 25 independent 39 -year samples. We report the average income and wealth distributions of our benchmark model economy in the second rows of Tables 1 and 6 respectively, and report the relative size of the fluctuations and the correlations with aggregate output of the model aggregates and of the income groups in the second rows of, Tables 3 and 4 respectively. $^{27}$

Our main findings are the following. First, we find that in this model economy, unemployment spells alone account for a small fraction of the concentration of income observed in the US economy (see the first panel of Fig. 3). Specifically, we find that the model economy's income Gini index (0.064) is only 18 percent of the income Gini index computed for the US economy using CPS data (0.351). Second, we find that the income distribution business cycle dynamics of this model economy differ significantly from the income distribution business cycle dynamics of the US economy. Third, we find that in this model economy, unemployment spells alone account for a small share of the concentration wealth observed in the US. Specifically, we find that the model economy's wealth Gini index (0.133) is also only 18 percent of the wealth Gini index

${ }^{27}$ The $R^{2}$ of the forecasting functions of the agents is 0.99999997 for the good shock and 0.99999997 for the bad shock. 
Table 6

Average wealth distributions

\begin{tabular}{|c|c|c|c|c|c|c|c|c|}
\hline \multirow[b]{2}{*}{ Economy } & \multirow[t]{2}{*}{ Gini } & \multicolumn{4}{|c|}{ Quintiles } & \multirow[b]{2}{*}{5 th } & \multicolumn{2}{|c|}{ Top groups $(\%$} \\
\hline & & $1 \mathrm{st}$ & $2 \mathrm{nd}$ & $3 \mathrm{rd}$ & 4 th & & $80-95$ & $95-100$ \\
\hline US & 0.757 & -0.60 & 1.80 & 5.70 & 13.40 & 79.70 & 25.80 & 53.90 \\
\hline Benchmark model & 0.133 & 13.63 & 17.13 & 19.57 & 22.26 & 27.41 & 19.45 & 7.96 \\
\hline P model & 0.117 & 14.77 & 17.46 & 19.14 & 21.44 & 27.09 & 19.43 & 7.66 \\
\hline PS model & 0.123 & 14.54 & 17.23 & 19.10 & 21.72 & 27.41 & 19.63 & 7.78 \\
\hline PSW model & 0.757 & -0.60 & 1.80 & 5.70 & 13.40 & 79.70 & 25.80 & 53.90 \\
\hline
\end{tabular}

Note: See notes to Table 1.

computed for the US economy using the 1992 Survey of Consumer Finances (SCF) (0.757).

As far as the income distribution business cycle dynamics are concerned, we find that in this model economy, the relative size of the fluctuations of the income share earned by the first quintile is more than one and one-half times larger than the one observed, while the relative size of the fluctuations of the share earned by the second quintile is only $25 \%$ of the one observed. Further, both the differences between the fluctuations of the income shares earned by the remaining groups and the differences between the correlations of the income shares and aggregate output are also large (see the first panels of Figs. 1 and 2). ${ }^{28}$

The first rows of Tables 3 and 4 also report, respectively, the relative volatilities and the correlations with output of the benchmark model economy aggregates. Note that the standard deviation of output and the relative standard deviation of employment have been targeted as part of our calibration choices and that, consequently, they are close to those observed. The relative volatilities of aggregate consumption and investment have not been targeted in our calibration. We find that they differ somewhat from their US economy counterparts: consumption in the model economy fluctuates less than in the US $(39 \%$ and $48 \%$ of output, respectively), and investment also fluctuates less (2.86 and 2.99 times the volatility of output, respectively). Another important fact that this model economy fails to reproduce is the large volatility of the income share

\footnotetext{
${ }^{28}$ Note that in spite of these large quantitative differences, the business cycle behaviors of the benchmark model and the US economies have some qualitative patterns in common. For instance, in both cases, the income shares earned by the first quintiles fluctuate more than the income shares earned by the rest of the groups, and, in both cases, the income shares earned by the first two quintiles are positively correlated with output.
} 

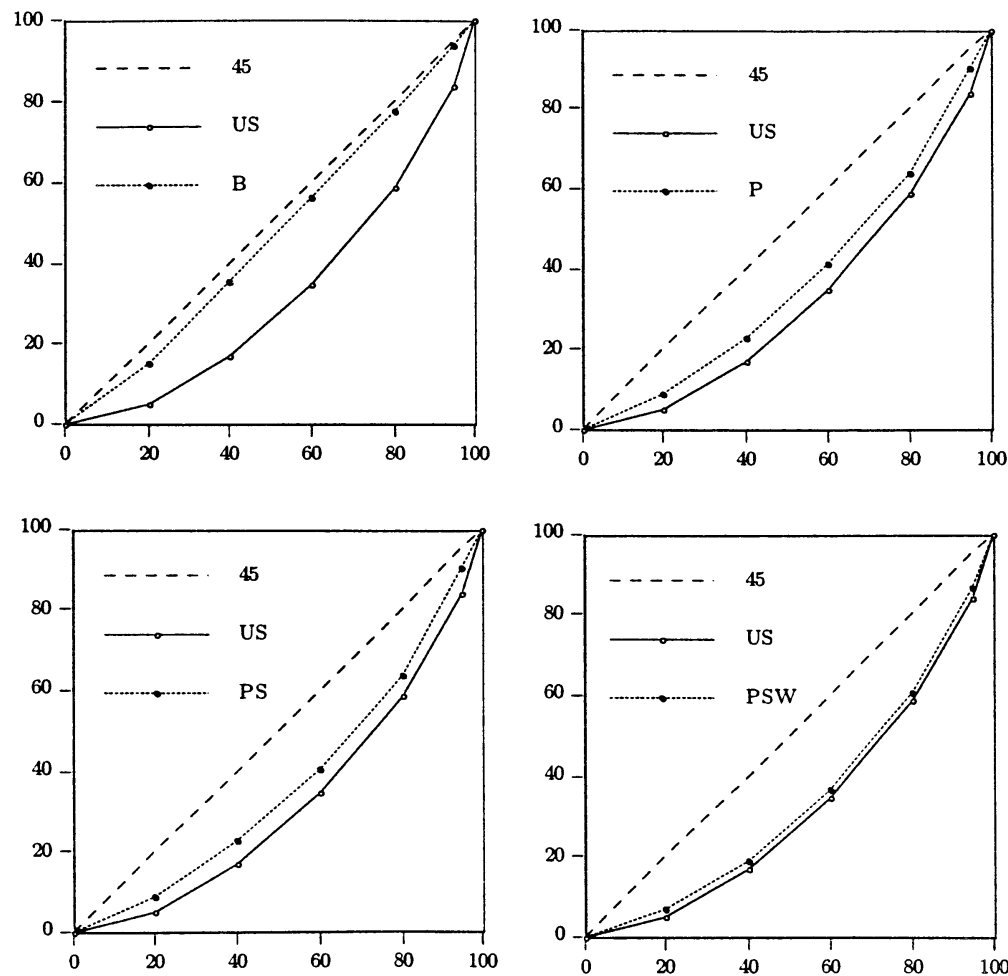

Fig. 3. The average income distributions (Lorenz curves) (the US economy and the benchmark, P, PS and PSW model economies).

earned by the top 5\%. Most probably, these large fluctuations in the income of the rich arise from reasons other than unemployment spells.

Some of the reasons for these findings are the following. First, since every household faces the same employment process, labor earnings are very uniformly distributed across households. Specifically, we find that households who experience long unemployment spells drop to the lowest earnings quintile, that those who experience short unemployment spells drop to the second lowest income quintile, and that the shares of labor earnings earned by the top three quintiles are exactly the same. ${ }^{29}$ Second, since every household faces the same

${ }^{29}$ This implies that the volatility of the income share earned by employed households - essentially those belong to the top $70 \%$ or $80 \%$ of the income distribution - is very similar to the volatility of aggregate output, while the volatility of the income share by the first quintile is significantly larger than the volatility of aggregate output. 
employment process, they all have the same incentives to save, and hence, it is not surprising that both capital and capital income turn out to be very uniformly distributed across households.

These reasons lead us to explore three successive extensions of our benchmark model economy, which we describe in the sections below.

\section{Multiple household types}

Our findings so far unambiguously show that in our benchmark heterogeneous household extension of the neoclassical growth model, uninsured unemployment spells alone generate a very small fraction of the income and wealth concentrations observed in the US. In this section, we introduce additional household heterogeneity, and explore the income distribution business cycle dynamics in a model economy in which households differ in their endowment of skills and in their employment processes.

Some of the reasons to model households that differ in their employment processes can be found in the labor economics literature. Clark and Summers (1981), Kydland (1984), Ríos-Rull (1993), amongst others, report that in the US economy, there is a tight inverse relationship between average wages and the volatility of individual employment. In this section, we model this relationship by partitioning the population into five household types that differ in their endowments of efficiency labor units, $\varepsilon_{i}$, and in the conditional transition probabilities on their type-specific employment process, $\pi_{i}\left(s^{\prime} \mid s, z, z^{\prime}\right)$. Consequently, the employment rates of the different household types, $N_{i}(z)$, also differ.

\subsection{Calibration}

The key issue in the calibration of this economy is how to partition households into groups. In this paper, we follow Ríos-Rull (1990) and Ríos-Rull (1993), who uses PSID data on wages to partition the population into five groups of equal sizes for males, females and the total population. ${ }^{30}$ For each of these groups, Ríos-Rull (1990) reports the average hours worked and the individual standard deviation of hours worked. In this paper, to proxy for households, we use Ríos-Rull's data on males. We do this because females work fewer hours and have lower wages than males. Hence, including the data on

\footnotetext{
${ }^{30}$ Recall that our data source for the income shares is the CPS and that the CPS uses top coding (it reports every household with earnings above a certain threshold, typically 100,000, as earning that threshold). Our procedure of grouping the population into five groups and of implicitly assuming that every member of the group has the same earnings effectively imposes top coding in the model economies.
} 


\begin{tabular}{llcccc}
\hline & \multicolumn{3}{c}{ Skill groups } \\
& First & Second & Third & Fourth & Fifth \\
\hline Efficiency factor & 0.509 & 0.787 & 1.000 & 1.290 & 2.081 \\
Average employment & 0.846 & 0.905 & 0.920 & 0.924 & $0.925^{*}$ \\
$\sigma_{i} / \bar{h}_{i}^{* *}$ & 0.284 & 0.245 & 0.220 & 0.199 & 0.156 \\
\hline
\end{tabular}

*Source: Ríos-Rull (1990).

${ }^{* *}$ The coefficient of variation of average hours.

females would have exaggerated both the earnings and the employment differentials across the model economy households.

\subsubsection{Population}

In the multiple household-type economy, the number of household types is $I=5$, and the mass of each type is $\mu_{i}=0.20$ for all $i$ (see Table 7).

\subsubsection{Technology}

As far as the employment opportunities for the different household types are concerned, we impose the following restrictions:

1. Labor efficiency factors. We assume that the labor efficiency factors for the different household types, $\varepsilon_{i}$, are the relative earnings of the different income groups that are reported in the first row of Table 7.

2. Average employment rates. Ríos-Rull (1990) reports the average annual hours worked in the market by each of the five types in which he partitions the PSID sample. As we have discussed above, in this paper, we abstract from variations in hours per worker. Consequently, we treat the variations in hours reported by Ríos-Rull as if they were variations in employment rates. We normalize the average employment rate of the median household type to $92 \%$, which is the average employment rate in the benchmark model economy. We report the relative average employment rates for each type in the second row of Table 7 . We use these rates as one of the two restrictions that we need to select the values for $N_{i}\left(z_{1}\right)$ and $N_{i}\left(z_{2}\right)$. For each type $i$, this restriction is that $\left(N_{i}\left(z_{1}\right)+N_{i}\left(z_{2}\right)\right) / 2$ equals its average employment rate.

3. The standard deviation of employment. The standard deviation of logged, detrended aggregate employment obtained from US annual data is $1.26 \%$. Ríos-Rull (1990) reports the average individual standard deviation of annual hours worked in the market for each of the five types in which he partitions the PSID sample. In the third row of Table 7, we report the coefficients of variation of yearly hours worked by the different skill types. We use these 
Table 8

Cyclical behavior of the PS economy: 39 yearly observations (deviations from trend)

\begin{tabular}{lcrrrrrr}
\hline & \multicolumn{7}{c}{ Cross correlations of output with } \\
Variable $(x)$ & $\sigma_{x}$ & $\sigma_{x} / \sigma_{y}$ & $x(t-2)$ & $x(t-1)$ & $x(t)$ & $x(t+1)$ & $x(t+2)$ \\
\hline Output $(y)$ & 2.63 & 1.00 & 0.07 & 0.54 & 1.00 & 0.54 & 0.07 \\
Consumption & 1.14 & 0.43 & -0.18 & 0.29 & 0.89 & 0.75 & 0.41 \\
Investment & 6.43 & 2.44 & 0.17 & 0.61 & 0.98 & 0.42 & -0.07 \\
Productivity & 1.38 & 0.52 & 0.00 & 0.48 & 0.96 & 0.69 & 0.29 \\
Employment & 1.28 & 0.49 & 0.15 & 0.60 & 0.99 & 0.44 & -0.05 \\
Labor share & 0.60 & 0.23 & -0.15 & -0.60 & -0.99 & -0.44 & 0.05 \\
& & & & & & & \\
Lowest quintile $(0-20 \%)$ & 3.31 & 1.26 & 0.19 & 0.62 & 0.97 & 0.38 & -0.11 \\
Second quintile (20-40\%) & 1.40 & 0.53 & 0.18 & 0.62 & 0.97 & 0.39 & -0.10 \\
Third quintile (40-60\%) & 0.06 & 0.02 & 0.33 & 0.71 & 0.85 & 0.17 & -0.31 \\
Fourth quintile (60-80\%) & 0.53 & 0.20 & -0.18 & -0.61 & -0.98 & -0.40 & 0.09 \\
Next 15\% (80-95\%) & 0.86 & 0.33 & -0.21 & -0.62 & -0.96 & -0.36 & 0.14 \\
Top 5\% (95-100\%) & 1.51 & 0.57 & -0.18 & -0.61 & -0.98 & -0.41 & 0.09 \\
\hline
\end{tabular}

statistics as the second restriction that we need to select the values for $N_{i}\left(z_{1}\right)$ and $N_{i}\left(z_{2}\right)$. Specifically, we make the standard deviation of employment of each type, $N_{i}\left(z_{1}\right)-N_{i}\left(z_{2}\right)$, proportional to the values reported in the third row of Table 7 . We choose the proportionality constant so that the volatility of aggregate detrended employment matches its counterpart in US data. The remaining household characteristics are the same for every household type, and they coincide with the corresponding ones in the benchmark model economy.

\subsection{Findings}

Once we have completely specified the functional forms and parameters of the multiple household-type model economy, we compute 25 independent 39-year samples. We report the average income and wealth distributions of this model economy in the third rows of Tables 1 and 6, respectively, and the relative size of the fluctuations and the correlations with aggregate output of both the model aggregates and the income shares earned by the different groups in the third rows of Tables 3 and 4, respectively. The full set of standard business cycle statistics are reported in Table $8 .{ }^{31}$

${ }^{31}$ The $R^{2}$ of the forecasting functions of the agents is 0.999999991 for the good shock and 0.999999988 for the bad shock. 
Our main findings are the following. First, we find that the multiple household-type economy is significantly more successful in replicating some of the key features of the US income distribution than the benchmark model economy (see the second panel of Fig. 3). Specifically, we find that in this model economy, the income shares earned by the different income groups, especially those earned by the three middle quintiles, are reasonably close to those observed in US data. The value of the approximated income Gini index in this model economy is 0.257 , which is still lower than the 0.351 observed in the US economy, but which is significantly higher than the 0.064 that obtains in the benchmark model economy.

Second, we find that the cyclical behavior of the income shares earned by the different groups in this model economy is reasonably close to the behavior displayed by US data. More specifically, our main findings are the following: (i) the relative volatility of the income share earned by the first quintile is 1.07 in the multiple household-type model economy, 1.69 in the benchmark model economy, and 1.07 in US data; (ii) the relative volatility of the income share earned by the second quintile is about 0.49 in the multiple household-type model economy, 0.13 in the benchmark model economy, and 0.48 in US data; (iii) the relative volatility of the income share earned by the $80-95 \%$ income group in the multiple household-type model economy is about three-fourths of the corresponding value observed in the US, and the same is true for the income share earned by the top $5 \%$ income group; (iv) compared to the benchmark model economy, the income share earned by the top $5 \%$ income group in the multiple household-type model economy is almost twice as volatile; (v) as far as the correlations between the income shares and aggregate output are concerned, we find that the correlations of the first five income groups in this model economy have the correct signs but are too large in absolute value and that the correlation of the income share earned by the top 5\% income group and aggregate output is way off: its correlation is almost -1 in the model economy and zero in US data; and (vi) roughly speaking, both the relative fluctuations of the income shares earned by the groups and their correlations with output start to display the observed hook-shapes (see the second panels of Figs. 1 and 2).

Third, we find that in the multiple household-type model economy, uninsured unemployment spells still account for a small share of the wealth concentration observed in the US economy. Specifically, we find that the wealth Gini index in this model economy (0.117) is only $15 \%$ of the one reported for the US economy by the SCF and that it is $12 \%$ smaller than the one that obtains in the benchmark model economy (0.133). In fact, we find that in the multiple household-type model economy, capital income is less concentrated than labor income. These last two features of the multiple household-type model economy arise because its equilibrium average real rate of return is smaller than the household's common subjective time discount rate, and therefore, the model economy households have little incentive to save. Moreover, low-skill types are 
subject to greater unemployment risk than high skill types, and therefore, their saving-to-income ratios are higher. ${ }^{32}$

\section{Cyclically moving factor shares}

The aggregate technologies used in the model economies described so far generate factor shares that are constant at every frequency. This is not the case in US data. As we report in the first rows of Tables 2-4, the US labor share fluctuates with the business cycle, it is countercyclical, and it leads output. Specifically, the standard deviation of labor share relative to that of output is 0.25 , its contemporaneous correlation with output is -0.10 , and the correlation of the two leads of the labor share and output is -0.42 .

In this paper, we do not investigate the causes that account for the countercyclical behavior of the labor share. ${ }^{33}$ We take this behavior as given, and we explore its implications for the behavior of the income distribution.

\subsection{Calibration}

To this purpose, in this model economy, we consider an aggregate production function that generates a countercyclical labor share under competitive pricing of the factors of production, even though it displays the same long-run properties as the Cobb-Douglas production function. This function is the following:

$$
f(K, L, z)=z K^{\theta+\eta(z)} L(z)^{1-\theta-\eta(z)},
$$

where $z$ is the productivity shock, and $\eta(z)$ is positive in expansions and negative in recessions. The expected value of $\eta(z)$ is zero, and it can be parameterized to mimic the variance of US factor shares. The values of $\eta(z)$ that result in the best approximation to the cyclical behavior of the US labor share are $\eta\left(z_{1}\right)=-\eta\left(z_{2}\right)=0.007 . .^{34}$

\footnotetext{
${ }^{32}$ Note that these findings imply that most of the success in replicating the US income distribution is accounted for by the distribution of labor income and, therefore, that it arises from the partition of households into five skill groups.

${ }^{33}$ Gomme and Greenwood (1995) document and discuss the cyclical behavior of factor shares. They ask whether this property is the outcome of risk-sharing contracts between relatively risk averse, low human capital workers and less risk averse, more talented entrepreneurs.
}

${ }^{34}$ This also requires changing the value of $z_{2} h_{2}\left(z_{2}\right)^{1-\theta-\eta\left(z_{2}\right)}$. It is now equal to 1.005 . 


\subsection{Findings}

First, we find that the absolute value of the contemporaneous correlation of the labor share and output is too large - it is -0.99 in this model economy and -0.10 in the data. Two reasons that justify this behavior of the model economy are that productivity shocks are the only source of aggregate fluctuations and that the process on these shocks takes two values only. ${ }^{35}$

Second, we find that the average behavior of the income distribution in the model economy with multiple household types and stochastic factor shares (the PS economy) is very similar to the one that obtains in the model economy with multiple household types and deterministic factor shares (the P economy). The third and fourth rows of Table 1 and the second and third panels of Fig. 3 illustrate this finding.

Third, we find that cyclical movements in factor shares similar in magnitude to those observed make very little difference for the income distribution business cycle dynamics. Specifically, we find that both the relative fluctuations of the income shares earned by the different groups and the correlations of these shares with aggregate output in the $\mathrm{P}$ and in the PS model economies are virtually the same (compare the third and fourth rows of both Tables 3 and 4 and the second and third panels of both Figs. 1 and 2).

\section{Exogenous wealth}

The main shortcoming of the multiple household-type model economy is its inability to account for the wealth distribution observed in the US economy. This task is not easy. Part of the differences in wealth across households is related to the life cycle, and our model economies abstract from life-cycle considerations. However, in the US economy, the observed wealth concentration is so large (the top quintile of the wealth distribution owns $80 \%$ of aggregate wealth, and the top $1 \%$ owns as much as $30 \%$ of aggregate wealth) ${ }^{36}$ that life-cycle features alone result in economies where wealth is still too disperse. In a recent paper, Quadrini and Ríos-Rull (1997) examine the wealth inequality literature, and they conclude that a successful account of the wealth concentration would have to include other features such as nonlinear budget constraints that would condition the savings decisions of both the wealthy and

\footnotetext{
${ }^{35}$ The $R^{2}$ of the forecasting functions of the agents is 0.99999998 for the good shock and 0.99999998 for the bad shock.

${ }^{36}$ See Díaz-Giménez et al. (1997) for a recent description of the US earnings, income, and wealth inequality facts.
} 
the dispossessed (increasing returns in the savings technology or income support policies are examples of such policies), other types of risk such as health risks or marital status risks (where divorce or illegitimacy would represent large negative shocks), or entrepreneurial activities in a context of incomplete outside financing.

These difficulties lead us to take the radical short-cut of imposing an exogenous wealth distribution onto our PS model economy. Our reason to do this is to explore whether or not the wealth distribution plays an important role in determining the model economies' income distribution business cycle dynamics. Specifically, in the model economy with multiple household types, cyclically moving factor shares and exogenous wealth (the PSW model economy) we impose that the joint distribution of earnings and wealth in the first period of each sample coincides with the joint distribution reported for the US by the 1992 SCF.

\subsection{Calibration}

To this purpose, we do the following. First, we use the 1992 SCF sample to construct a measure of the joint distribution of labor earnings and wealth for the US economy. Next we use the first eight model periods of the stochastic realizations of the PS model economy to compute its average yearly earnings distribution. Then we use this average earnings distribution to construct a sample of households of the PS model economy that is similar to the one reported by the SCF for the US economy, and sort the households in both the $\mathrm{SCF}$ and the PS model economy samples according to their earnings. Then we assume that a household in the $h$ th position in the model economy earnings ranking owns the same share of total wealth as the household in the $h$ th position in the SCF sample, and we denote this share by $\lambda_{h}$. Then we use the householdspecific shocks, $s_{h t}$, factor prices, $r_{t}$ and $w_{t}$, and aggregate capital, $K_{t}$, from the stochastic realizations of the PS model economy to construct an income series for each household in the exogenous wealth model economy sample. This definition of income is the following:

$$
y_{h t}=s_{h t} w_{t}+\lambda_{h} K_{t} r_{t} .
$$

Next we aggregate the income of each household from the model period to the data collecting period, and finally, this income panel is used to compute for the exogenous wealth model economy the same statistics that we compute for the endogenous wealth model economies. ${ }^{37}$

\footnotetext{
${ }^{37}$ Note that this method depends crucially on the fact that we have assumed that households choose to work whenever that option is available to them. Also note that this method is silent about the individual household consumption/investment split.
} 


\subsection{Findings}

We report the average income and wealth distributions of our model economy with multiple household types, stochastic factor shares and exogenous wealth in the last rows of Tables 1 and 6, respectively, and also the relative size of the fluctuations and the correlations with aggregate output of the model aggregates and of the income groups in the last rows of, respectively, Tables 3 and 4.

Our main findings are the following: First, in the PSW model economy, unemployment spells alone account for a large share of the observed concentration of income (see the fourth panel of Fig. 2). Specifically, the value of the approximated Gini index in this model economy is 0.315 , which is 90 percent of the value obtained for the US economy using CPS data $(0.351){ }^{38}$

Second, imposing the US wealth distribution exogenously on the PS model economy leaves its income distribution business cycle dynamics roughly unchanged (compare the last two rows of both Tables 3 and 4 and the third and fourth panels of Figs. 1 and 2). More specifically, the main difference between the PS and the PSW model economies is the business cycle behavior of the income share earned by the third quintile: while its relative volatility is higher in the PSW model economy ( 0.22 versus 0.03$)$, its correlation with output is smaller (0.73 versus 0.92$)$.

\section{Concluding comments}

In this paper, we explore the role played by unemployment spells and cyclically moving factor shares in determining the income distribution dynamics. To this purpose, we analyze different heterogeneous household extensions of the neoclassical growth model.

In the first model economy, we assume that households are ex ante identical and that they are subject to the same employment process. We find that in this model economy, uninsured unemployment spells fail to account either for the income concentration observed in the data or for the income distribution business cycle dynamics.

In the second model economy, we partition the households into five skill types that differ in their endowment of efficiency labor units and in the first two moments of their calibrated employment processes. We find that in this model economy, uninsured unemployment spells do a fair job in accounting both for the income distribution observed in the US and for many aspects of its business cycle dynamics. We also find that this model economy fails to display the wealth concentration observed in the US.

\footnotetext{
${ }^{38}$ It goes without saying that, by construction, the model economy with multiple household types and exogenous wealth replicates the observed wealth distribution exactly.
} 
In the third model economy, we modify the standard aggregate technology so that it displays cyclically moving factor shares calibrated to those observed. We find that the effects of including this feature on both the income and wealth distributions and on the income distribution business cycle dynamics are insignificant.

In the last model economy, we impose the US wealth distribution exogenously on the model economy with five household types and cyclically moving factor shares. We find that including this feature leaves the income distribution business cycle dynamics essentially unchanged.

These findings lead us to conclude the following. (i) Partitioning the population into five types subject to type-specific employment processes seems to be enough to account for most aspects of the income distribution business cycle dynamics. More specifically, it seems that most aspects of the income distribution arise from the differences in the frequency of unemployment across types and that we can abstract from business cycle variations in both hours and wages across types. (ii) Cyclically moving factor shares do not seem to play a significant role in accounting for the main aspects of the income distribution business cycle dynamics. (iii) The income distribution business cycle dynamics may be essentially independent from the significant part of the observed wealth concentration that these model worlds do not succeed in explaining - that is, although in real economies capital income is very concentrated, the part that the model fails to explain may be orthogonal to the business cycle dynamics of the income shares earned by the different income groups. If this conclusion is correct, it would mean that in the same way that fluctuations in the capital input play a small role in accounting for the aggregate business cycle, capital income fluctuations may play a small role in accounting for the income distribution business cycle dynamics.

As far as the wealth distribution is concerned, like most recent research on distribution (see Quadrini and Ríos-Rull (1997)), this paper begs the question of what it is that makes the wealth distribution so extremely concentrated. Unfortunately, the role played by our chosen candidates - unemployment spells and cyclically moving factor shares - has proven to be small. As far as the study of business cycles is concerned, the cyclical behavior of purchases of consumer durables and of investment in housing is still understood poorly, and the fact that they seem to lead the cycle is still an open question. These two activities are large, relative to the yearly income earned by most households, and, in environments where lotteries are not available, their study may require the use of models not unlike the ones analyzed in this paper.

\section{Acknowledgements}

We are grateful for the comments of Paul Gomme, Ed Green, Robert Lucas, Per Krusell, Albert Marcet, Ed Prescott, Vincenzo Quadrini, Richard Rogerson, 
Randy Wright, Stan Zin and an anonymous referee. We also thank the participants at the NBER Summer Institute, Northwestern Conference in Applied General Equilibrium, and the seminars at the Institute for International Economic Studies, University of Pennsylvania and Universitat Pompeu Fabra (twice). Díaz-Giménez thanks the DGICYT for grant PB94-0378. Ríos-Rull thanks the National Science Foundation for grant SBR-9309514.

\section{Appendix A. Data}

This section describes the methods that we use to construct the aggregate data for the US economy. Most of these methods follow Cooley and Prescott (1995), except that we abstract from the government. Specifically, we do the following:

- We define output as GDP plus imputed services from the stock of consumer durables. The stock of consumer durables is taken from Musgrave (1992). We assume that the rate of return on durables is the same as the rate of return on the standard measure of the capital stock. To compute this rate of return, we use NIPA data, assume a constant depreciation rate, and follow the procedures described in Cooley and Prescott (1995). To calculate the depreciation rate, we assume that the economy is on a balanced growth path.

- The series for consumption includes nondurables, services, and the imputed flow of services from the stock of consumer durables net of depreciation.

- The series for investment includes the NIPA definition of investment plus purchases of consumer durables.

- We define the capital income share as the ratio of capital income to total output. To construct the capital income series, we consider rental income of persons, capital consumption allowances, corporate profits, and net interest income as unambiguous capital income; we consider compensation of employees as unambiguous labor income; and allocate the remaining components of the NIPA measure of income to capital and labor in the same proportions as those of unambiguous labor income and unambiguous capital income to the sum of these two variables. ${ }^{39}$

- For the series for hours worked, we use the Household Survey data.

- Note that Table 2 reports the standard business cycle facts that obtain from yearly data; namely, consumption and investment are strongly correlated

\footnotetext{
${ }^{39}$ The remaining components of the NIPA measure of income are proprietor's income, indirect business taxes, nontax liabilities, business transfer payments, and statistical discrepancies.
} 
with output, investment is about six times more volatile than consumption and three times more volatile than output, average labor productivity is about $75 \%$ as volatile as output, and employment is about $50 \%$ as volatile as output.

\section{Appendix B. Computation}

\section{B.1. Approximating the equilibrium}

In our model economy, like most in recursive models, we can define an operator, $T$, that maps a suitable set of laws of motion of the economywide state, into itself; that is, $T: G \mapsto G$, where $G \subset\left\{g: \mu^{\prime}=g(\mu, z)\right\}$. More specifically, operator $T$ returns the law of motion of $\mu, T g(\mu, z)$ implied by the household optimal decisions that take as given a law of motion for $\mu, g(\mu, z)$ as part of the specification of the decision problem. The fixed points of this class of operators are part of the equilibria of these models, and therefore, successive approximations on these operators are frequently used in the algorithms that compute these equilibria. In our case, however, the large size of the elements of $G$ makes it very hard to implement this operator in the computer. ${ }^{40}$

To overcome this problem, we use a different operator, which we define over a much smaller space, and in which a fixed point can be readily computed. This new operator is associated to an economy similar to the one described in Section 4, but with 'boundedly rational' households. The gist of its logic is to approximate the distribution, $\mu$, by a small set of functions as follows. ${ }^{41}$

Let $q_{j}(\mu)$ be a multivariate function that maps the space of measures into $\mathbb{R}^{j},{ }^{42}$ where function $q_{j}(\mu)$ must be chosen so that $\left\{q_{j}(\mu), z\right\}$ includes a sufficient statistic for factor prices, and let $h_{j}\left(q_{j}, z\right)$ be a linear function that maps $\mathbb{R}^{j} \times Z$ into $\mathbb{R}^{j}$, where function $h_{j}(\cdot)$ is used to predict the values of $q_{j}\left(\mu^{\prime}\right) .{ }^{43}$ Consider the following problem where we implicitly assume that the maximization is

${ }^{40}$ Recall that the state space includes a time-varying distribution of assets and employment opportunities.

${ }^{41}$ See Krusell and Smith (1996) for an exhaustive description of this class of approximations. In their paper, essentially they show that approximating the wealth distribution by its first moment is sufficiently good for our purposes.

${ }^{42}$ Function $q_{j}(\cdot)$ could map the set of measures into its first $j$ moments, for instance.

${ }^{43}$ In fact, the function $h_{j}\left(q_{j}, z\right)$ does not need to be linear - any parametric family of functions will do, but Krusell and Smith (1996), Krusell and Smith (1997), report that linear functions are very good predictors of the future moments of $\mu$. 
subject to the budget constraint and factor pricing functions and where, to simplify the notation, we define $x \equiv q_{j}(\mu)$ :

$$
v\left(a, x, s, z ; h_{j}, q_{j}\right)=\max _{c \geqslant 0, a^{\prime} \in \mathscr{A}}\left\{u(c)+\beta E\left[v\left(a^{\prime}, x^{\prime}, s^{\prime}, z^{\prime} ; h_{j}, q_{j}\right) \mid s, z\right]\right\}
$$

such that

$$
x^{\prime}=h_{j}(x, z) .
$$

Note that we have indexed the value function described in Eq. (10) both by function $q_{j}(\cdot)$ that returns the functions that proxy for measure $\mu$ as state variables and by the predictor function $h_{j}(\cdot)$ that returns the future values of those functions. The households that solve this problem can be said to be 'boundedly rational' in several ways. First, when households predict the future values of prices, they do not use all the information at their disposal. Instead, they approximate the distribution by a finite set of its functions. Second, they consider only the current-period values of these functions to predict their future values. Finally, in their forecasts of $x^{\prime}$, they do not take into account the prediction errors. ${ }^{44}$

Once the expressions for the budget constraint and for factor prices have been substituted into the program defined in Eq. (10), its solution is an optimal savings rule $a^{\prime}\left(a, x, s, z ; h_{j}, q_{j}\right)$, which, together with the process on $z$, generates a law of motion for the economy, $g\left(\mu, z ; h_{j}, q_{j}\right)$. Let $b_{j}\left(q_{j}, h_{j}\right)$ denote the best, linear, unbiased forecaster of $q_{j}\left(\mu^{\prime}\right) .{ }^{45}$ Successive approximations can now be used to obtain a fixed point in the space of predictor functions, $h_{j}^{*}=b_{j}\left(q_{j}, h_{j}^{*}\right)$. This fixed point is an essential part of any equilibrium in a model world with 'boundedly rational' households, since it must be the case that when the households use linear predictor $h_{j}^{*}(\cdot)$, their behavior generates a law of motion in which the best linear predictor is also $h_{j}^{*}(\cdot)$.

Since a given distribution, $\mu$, can be approximated by a large class of functions, $q_{j}(\mu)$, and since these functions in general have different predictor functions, $h^{*}\left(q_{j}\right)$, we are not done yet. We still have to single out the 'correct' form of function $q_{j}(\cdot)$. We do this as follows: Let $\left\{q_{j}(\mu)\right\}_{j=1}^{\infty}$ be a nested sequence of $j$-dimensional functions of measure $\mu$ such that it contains at least every moment of that measure in its natural order. Our objective is to find a function $q_{j}(\cdot)$ of small dimension $j$, which has the property that economies in which the

\footnotetext{
${ }^{44}$ Most numerical approximations to compute equilibria impose a form of certainty equivalence that avoids this problem. We do not think that this issue is quantitatively important.

${ }^{45}$ Note that $b_{j}$ maps the space of linear $j$-dimensional functions into itself and that it can be readily computed through long simulations. Again, as with function $h_{j}$, the $b_{j}$ does not need to be linear. However, both functions must belong to the same family.
} 
households approximate the wealth distribution using functions of a larger dimension display a similar equilibrium behavior.

To determine whether the equilibrium behavior of two economies is similar, we have to choose a metric that allows us to compare that behavior. There are several candidates for this metric. Two such candidates are the distance between the stochastic realizations of the economies and the distance between the optimal decision rules, $a_{j}^{\prime}$. The procedure that we use in this paper to determine whether the equilibrium behavior of two economies is close is the following. First, we choose a function $q_{j}(\cdot)$, compute its associated equilibrium predictor, $h^{*}\left(q_{j}\right)$, and then construct a measure of the predictive accuracy of this predictor (its $R^{2}$ or the variance of the one-period ahead forecasting errors, for example). ${ }^{46}$ Next we choose a multivariate function of dimension $j+1, q_{j+1}(\cdot)$, such that $q_{j}(\cdot) \subset q_{j+1}(\cdot)$, and compute the accuracy of the best forecasts of $q_{j}\left(\mu^{\prime}\right)$, conditional on $\left\{q_{j+1}(\mu), z\right\}$. This predictive accuracy is compared with the accuracy of the forecasts of $q_{j}\left(\mu^{\prime}\right)$, based on $h^{*}\left(q_{j}(\mu), z\right)$. If the difference in predictive accuracies is small, we conclude that the approximation to the equilibrium with 'boundedly rational' households that use $q_{j}(\cdot)$ is satisfactory. Otherwise, we use $q_{j+1}(\cdot)$ to approximate the distribution, and repeat this procedure for $q_{j+2}(\cdot)$.

In this paper, we follow Krusell and Smith (1996), hence choose $j=1$, and $q_{1}(\mu)$ is defined to be aggregate capital. This approximation turns out to work remarkably well.

\section{B.2. The computational algorithm}

The outline of the computational algorithm used is the following:

Step 1: Choose the vector of functions, $q_{j}$.

Step 2: Choose an initial prediction function, $h_{j 0}(x, z)$, where $x \equiv q_{j}(\mu)$.

Step 3: Given $h_{j 0}$, solve the household decision problem described in (10) and obtain the vector of household decision rules, $a_{j}^{\prime}\left(a, x, s, z ; h_{j 0}, q_{j}\right)$.

Step 4: Given $a_{j}^{\prime}\left(a, x, s, z ; h_{j 0}, q_{j}\right)$, simulate a long realization of the economy and obtain a new prediction function, $h_{j 1}(x, z)$, by ordinary least squares.

Step 5: If $h_{j 0}(x, z)=h_{j 1}(x, z)$, go to Step 6. Otherwise, use a weighted average of $h_{j 0}$ and $h_{j 1}$ to update $h_{j 0}(x, z)$ and go to Step 3 .

Step 6: Add another function to the vector of functions $q_{j}$ that now becomes $q_{j+1}$ and compute a regression of $q_{j}\left(\mu^{\prime}\right)$ on $\left\{q_{j+1}(\mu), z\right\}$. If the $R^{2}$ increases more than a certain bound, then let $j=j+1$ and go to Step 2. Otherwise, we are done.

${ }^{46}$ The continuity of the decision rules with respect to predicted values of $q_{j}\left(\mu^{\prime}\right)$ guarantees that small prediction improvements imply small changes in the resulting actions. This property relates the metric defined on the accuracy of the predictor to the metric defined on the decision rule space. 
The outline of the algorithm used to solve the household decision problem is the following: ${ }^{47}$

Step 3.1: Impose a grid on the household-state space $\left\{\mathscr{A} \times \mathscr{R}^{j} \times \boldsymbol{S} \times \boldsymbol{Z}\right\}$.

Step 3.2: Initialize the savings decision rule $a_{j 0}^{\prime}(a, x, s, z)$ in the grid points and assume that it is piecewise linear in the remaining points of set $\mathscr{A}$.

Step 3.3: For each point in the grid, find the value of $a^{\prime}$ that solves the Euler equation of the household decision problem described in Eq. (10); namely,

$$
u^{\prime}\left(a^{\prime}, a, x, s, z\right)=\beta \sum_{s^{\prime}, z^{\prime}} r\left(x^{\prime}, z^{\prime}\right) u^{\prime}\left[a_{j 0}^{\prime}\left(a^{\prime}, x^{\prime}, s^{\prime}, z^{\prime}\right), a^{\prime}, x^{\prime}, s^{\prime}, z^{\prime}\right] \Gamma\left(s^{\prime}, z^{\prime} \mid s, z\right) .
$$

Note that given the prediction function, $x^{\prime}=h_{j 0}(x, z)$, Eq. (11) is a function of $(a, x, s, z)$ only and that, therefore, it can be solved for $a^{\prime}=a_{j 1}^{\prime}(\cdot)$.

Step 3.4: If $a_{j 1}^{\prime}(\cdot)=a_{j 0}^{\prime}(\cdot)$ in every grid point, we are done. Otherwise, update $a_{j 0}^{\prime}(\cdot)$ and go to Step 3.3.

\section{References}

Aiyagari, S.R., 1994. Uninsured idiosyncratic risk and aggregate saving. Quarterly Journal of Economics 109, 659-684.

Atkeson, A., Lucas, R.E. Jr., 1992. On efficient distribution with private information. Review of Economic Studies 59, 427-453.

Atkeson, A., Lucas, R.E. Jr., 1995. Efficiency and equality in a simple model of efficient unemployment insurance. Journal of Economic Theory 66, 64-88.

Backus, D.K., Kehoe, P.J., 1992. International evidence on the historical properties of business cycles. American Economic Review 82, 864-888.

Banerjee, A.V., Newman, A.F., 1993. Occupational choice and the process of development. Journal of Political Economy 101, 274-298.

Clark, K.B., Summers, L.H., 1981. Demographic differences in cyclical employment variation. Journal of Economic Resources 16, 61-79.

Cooley T.F., Prescott E.C., 1995. Economic growth and business cycles. In: Cooley, T. (Ed.), Frontiers of Business Cycle Research, Princeton University Press, Princeton, NJ, pp. 1-38.

Díaz-Giménez J., 1990. Business cycle fluctuations and the cost of insurance in computable heterogeneous agent monetary economies. Ph.D. dissertation, University of Minnesota.

Díaz-Giménez J., 1997. Uninsured idiosyncratic risk, liquidity constraints and aggregate fluctuations. Economic Theory 10, 463-482.

Díaz-Giménez J, Prescott, E.C, 1997. Real returns on government debt: a general equilibrium quantitative exploration. European Economic Review 41, 115-137.

Díaz-Giménez J, Prescott, E.C, Fitzgerald, T, Alvarez, F, 1992. Banking in computable general equilibrium economies. Journal of Economic Dynamics and Control 16, 533-559.

Díaz-Giménez, J, Quadrini, V, Ríos-Rull, J.-V, 1997. Dimensions of inequality: facts on the US distributions of earnings, income, and wealth. Federal Reserve Bank of Minneapolis Quarterly Review 21, 3-21.

${ }^{47}$ Huggett (1993) uses a similar algorithm. 
Gomme, P, Greenwood, J, 1995. On the cyclical allocation of risk. Journal of Economic Dynamics and Control 19, 91-124.

Huggett, M., 1993. The risk-free rate in heterogeneous-agent incomplete-insurance market economies. Journal of Economic Dynamics and Control 17, 953-969.

İmrohoroğlu A, 1989. Cost of business cycles with indivisibilities and liquidity constraints. Journal of Political Economy 97, 1364-1383.

İmrohoroğlu A, 1992. The welfare cost of inflation under imperfect insurance. Journal of Economic Dynamics and Control 16, 79-91.

İmrohoroğlu A. Prescott, E.C, 1991. Seigniorage as a tax: a quantitative evaluation. Journal of Money, Credit and Banking 23, 462-475.

Kocherlakota, N.R., 1996. The equity premium: it's still a puzzle. Journal of Economic Literature 34, 42-71.

Krusell P., Smith A., 1996. Income and wealth heterogeneity in the macroeconomy. Unpublished manuscript. University of Rochester.

Krusell P., Smith A., 1997. Income and wealth heterogeneity, portfolio choice, and equilibrium asset returns. Unpublished manuscript. University of Rochester.

Kydland, F.E., 1984. Labor-force heterogeneity and the business cycle. Carnegie-Rochester Conference Series on Public Policy 21, 173-208.

Mehra, R., Prescott, E.C., 1985. The equity premium: a puzzle. Journal of Monetary Economics 15, 145-161.

Musgrave, J.C., 1992. Fixed reproducible tangible wealth in the United States: revised estimates. Survey of Current Business 72, 106-107.

Quadrini, V., Ríos-Rull, J.-V., 1997. Understanding the US distribution of wealth. Federal Reserve Bank of Minneapolis Quarterly Review 21, 22-36.

Ríos-Rull, J.-V., 1990. Topics in stochastic overlapping generations economies. Ph.D. dissertation. University of Minnesota.

Ríos-Rull, J.-V., 1993. Working in the market, working at home and the acquisition of skills: a general equilibrium approach. American Economic Review 83, 893-907.

Ríos-Rull, J.-V., 1994. On the quantitative importance of market completeness. Journal of Monetary Economics 34, 463-496.

Ríos-Rull, J.-V., 1996. Life-cycle economies and aggregate fluctuations. Review of Economic Studies 63, 465-489. 